(6)

\section{OPEN ACCESS}

${ }^{1}$ World History Center, University of Pittsburgh, Pittsburgh, Pennsylvania, USA ${ }^{2}$ Ontario Tobacco Research Unit, University of Toronto, Toronto, Canada

${ }^{3}$ Institute for Global Tobacco Control, Johns Hopkins University, Baltimore, Maryland, USA

\section{Correspondence to} Dr Mat Savelli, World History Center, University of Pittsburgh, 3900 Posvar Hall, Pittsburgh, PA 15260, USA; matsavelli@gmail.com

Received 18 June 2013 Accepted 23 September 2013 Published Online First 20 November 2013
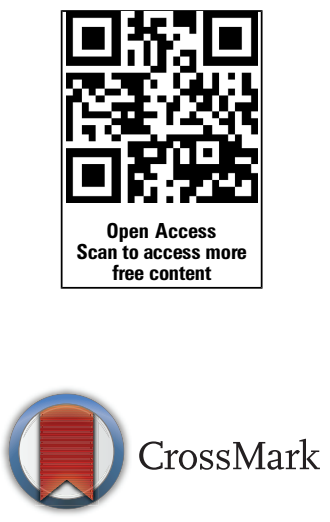

To cite: Savelli $M$ O'Connor SC, Di Sante $E_{\text {, }}$ et al. Tob Control 2015;24:303-305.

\title{
Packaging digital culture to young smokers
}

\author{
Mat Savelli, ${ }^{1}$ Shawn C O'Connor, ${ }^{2}$ Emily Di Sante, ${ }^{2}$ Joanna E Cohen ${ }^{3}$
}

Tobacco companies frequently seek to associate their products with certain lifestyle images in an attempt to foster brand-specific identities for their cigarettes. As demonstrated by industry-sourced segmentation analyses, for example, companies divide smokers into broad groups based on personal characteristics and strategise on how to adapt their products to increase attractiveness for these imagined communities. ${ }^{1-3}$ Linking tobacco products with the hallmarks of the digital age, such as social media and innovative technologies, seems to have become a marketing goal for a number of tobacco companies. ${ }^{4-6}$ Indeed, several studies have hypothesised that the use of mobile phones and smoking may be connected (either as complimentary or competing behaviours) in light of the fact that these products may provide users with opportunities for identity formation and rebellion. ${ }^{7-9}$ Drawing from a larger study of top selling international brands, we report three illustrative case studies which underscore a recognisable pattern of digital culture in package design.

Between July 2011 and January 2012, we collected a sample of top market share cigarette brands comprising 193 cigarette packages from 23 countries as part of the wider Chatter Box project hosted at the University of Toronto's Ontario Tobacco Research Unit. The countries targeted were culturally diverse, drawn from five continents (North America, South America, Europe, Asia and Australia). Using a combination of qualitative content analysis and semiotic analysis, we identified a common theme of 'digital culture' among a series of packs from countries including South Korea, Japan, Lebanon, Switzerland, Italy, Belgium, Russia, Serbia, the Netherlands and the USA.

Kent has taken a leading position in using the concept of digitalism through Kent Convertibles (known alternately as the Kent Switch). The most noticeable design feature is the modified IEC 5009 'power' switch that is used on many types of electronics and which has become something of an icon for the digital age, adorning t-shirts, coffee mugs and underwear. The way this 'switch' is positioned may encourage smokers to 'click' the switch as they open the pack, symbolically turning the pack on. The cigarettes themselves also carry the 'power switch' button. The top of the pack usually contains the word 'Convertibles' with the 'o' and ' $n$ ' located within a red circle, creating the shape of an 'on' button (figure 1). The notion of technology is underlined by instructions on the pack telling the smoker to 'Click to Switch'-a reference noting that the cigarette can be converted to a menthol cigarette by crushing a small ball contained within the filter. The digital theme of the pack may represent an attempt to highlight the technology of the crushable filter. According to a spokesman for British American Tobacco (BAT), the launch of the Switch/Convertibles sub-brand was 'the largest scale activity in the history of BAT Russia' ensuring that 'BAT is well positioned to take advantage of this new technology. ${ }^{10}$ Other Kent packs play on themes of digital culture including HD, Surround and Nanotek (figure 2).

The signature element of the Marlboro Beyond, meanwhile, is the 'Iceball' which smokers crush to switch the cigarette to a menthol cigarette. Although the Iceball itself is a round pellet, the holographic image of it on the pack is more akin to a camera lens with a series of small diminishing rings. This feature links the pack with one of the hallmarks of digital culture, the smartphone. The pack is roughly the same size as many phones and the placement of the Iceball 'camera lens' is significant-so much so that the iconic Marlboro chevron has been displaced sideways to allow for its placement. Indeed, in Canada's federal trademark database, Phillip Morris has registered the symbol and described it as an 'optical lens.' ${ }^{11}$ The displacement of the chevron, meanwhile, creates what looks like an iPod's 'play button' (figure 3). Inside the Swiss pack, an insert explains the 'Iceball technology' and provides a customer code to access the Marlboro's website-furthering the association among the cigarette, the smoker and digital technology.

The L\&M Orange and Blue packs are also firmly rooted in the digital world, decorated with clouds that contain replicas of the 'skip track' buttons found on mp3 players and iPods. The side of the pack features the 'rock on' symbol being given by a 'hyperlink hand,' replicating the image that appears when a cursor is moved over an internet link. The
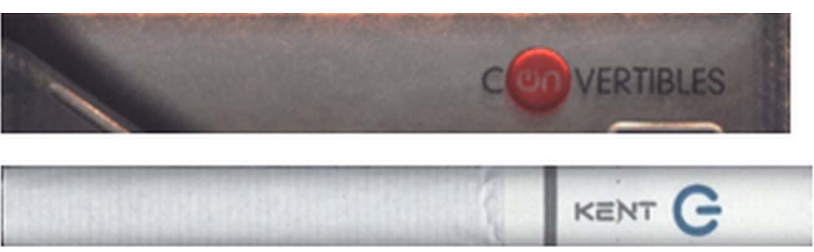

Figure 12012 Kent Convertibles (Netherlands) and IEC 5009 Power Button. 

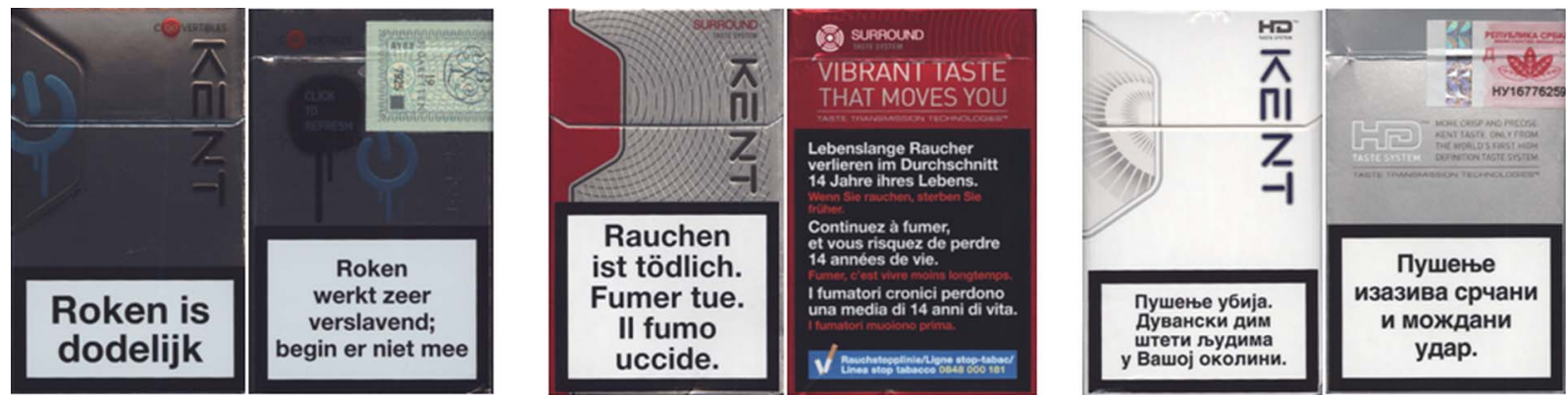

Figure 22012 Kent Convertibles (Netherlands), Surround (Switzerland) and HD (Serbia) packs.

Figure 32012 Marlboro Beyond (Switzerland) and iPhone camera lens.

Figure 42012 L\&M Blue Pack (Switzerland).
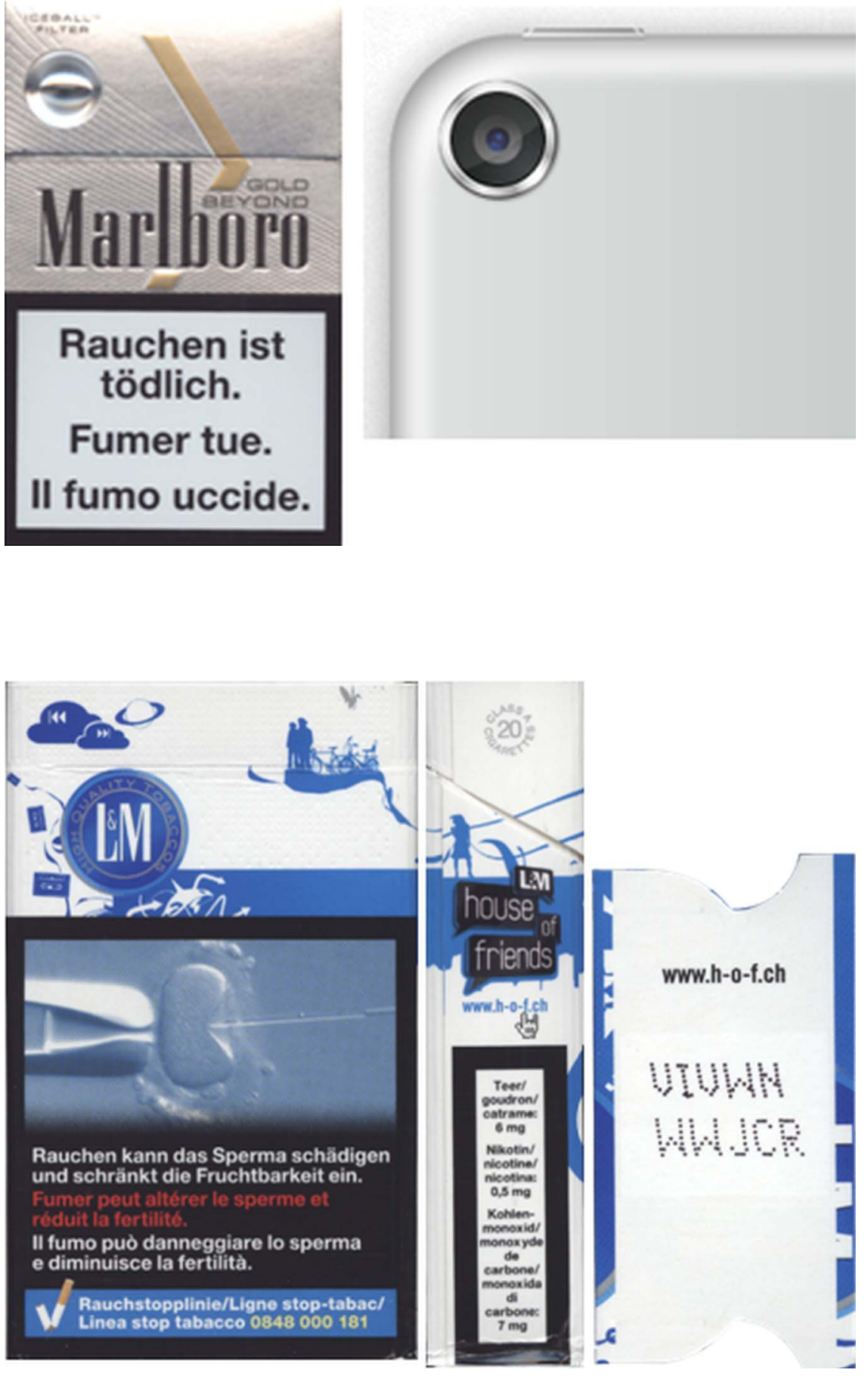
side of the pack directs smokers to a website entitled the 'House of Friends' (figure 4) which may represent an attempt to foster an association with the culture of web-based social networking provided by websites such as Facebook, Instagram and Twitter. A pack insert gives further instructions on how to log on to the House of Friends where smokers can 'win prizes for spending good times with your friends' including videogame systems and a digital camera.

One ramification of the link with digital culture is that packs now provide consumers with new ways to engage with tobacco companies. The packs frequently direct consumers to interactive online content (such as the House of Friends) which may be an attempt to foster a sense of community and belongingness among smokers. Given the diminishing ability of tobacco manufacturers to advertise using traditional mediums, the internet serves as a vital arena to engage consumers. Indeed, this reflects the advice given to RJ Reynolds by a market research firm: 'Ride the wave of the Internet's influence. With television losing its ability to affect consumer interest, tap into the Internet's unprecedented ability to reach ASU30s [adult smokers under 30]. ${ }^{, 12}$

The utilisation of key touchstones of digital culture may also imply that these cigarettes are meant for those who are young, modern and digitally literate. In the words of the global account director for MeadWestvaco (the firm responsible for some of Kent's packaging innovations including a digitally-infused carton), BAT's target audience are 'hip, affluent, early-adopting consumers. ${ }^{13}$ The packs, through their association with iconic items of the digital age, may be attempting to become 'extensions of the self' in the way that smartphones represent not only useable items but an intrinsic part of a user's identity. ${ }^{14}$ Given the special place occupied by mobile digital technology as a hallmark of status, belonging, and independence for teenagers and other young people, ${ }^{15-17}$ cigarette packs that share a stylistic similarity to popular handheld devices (such as smartphones and digital music players) may perhaps reflect a desire to associate these packs with other 'must have' and 'never leave home without it' consumer goods.

Acknowledgements We would like to thank the larger Chatter Box team for their continued support.

Contributors MS did the bulk of the primary research and writing of the article. SCO'C and EDS contributed to the writing of the article and assisted in the primary research. JC consulted throughout the process of the primary research and contributed to the writing of the article.

Funding This study forms part of a larger research project (The Chatter Box Project). Production of this research has been made possible through a financial contribution from Health Canada. The views expressed herein do not necessarily represent the views of Health Canada.

Competing interests None.
Provenance and peer review Not commissioned; externally peer reviewed.

Open Access This is an Open Access article distributed in accordance with the Creative Commons Attribution Non Commercial (CC BY-NC 3.0) license, which permits others to distribute, remix, adapt, build upon this work non-commercially, and license their derivative works on different terms, provided the original work is properly cited and the use is non-commercial. See: http://creativecommons.org/ licenses/by-nc/3.0/

\section{REFERENCES}

1 RJ Reynolds. US Segmentation and Portfolio Recommendation. 2006. Bates No: 545257630-7728. http://legacy.library.ucsf.edu/tid/gyc87h00 (accessed 3 Sep 2013).

2 Brown and Williamson. 1996 Segmentation Study. 1996. Bates No: 439030149/ 0168. http://legacy.library.ucsf.edu/tid/sqt12d00 (accessed 4 Sep 2013).

3 Phillip Morris. Virginia Slims Female Segmentation Study Presentation. 2002. Bates No: 3006823635/3006823679. http://legacy.library.ucsf.edu/tid/xek20i00 (accessed 4 Sep 2013).

4 RJ Reynolds. Enter for a Chance to Win an iPod Video $+\$ 1000$ iTunes Music Card. 2007. Bates No: 534279393/9394. http://legacy.library.ucsf.edu/tid/eaj21b00 (accessed 18 Aug 2013).

5 RJ Reynolds. Strategies and Objectives. 1999. Bates No: 520449933-9940. http:// legacy.library.ucsf.edu/tid/piv08j00 (accessed 18 Aug 2013).

6 RJ Reynolds. Winston "Chrome" Alternative Brand Positioning and Visual Branding Concepts. 2000. Bates No: 526250818-0837. http://legacy.library.ucsf.edu/tid/ eup15j00 (accessed 18 Aug 2013).

7 Charlton A, Bates C. Decline in teenage smoking with rise in mobile phone ownership: hypothesis. BMJ 2000;321:1155.

8 Peretti-Watel P, Legleye S, Beck F. Cigarettes and mobile phones: are they complementary or substitutable products? Drugs: Educ Prev Policy 2002;9:339-43.

9 Cassidy S. Using social identity to explore the link between a decline in adolescent smoking and an increase in mobile phone use. Health Educ 2006;106:238-50.

10 Cobben M. BAT Capsule Rollout Presentation. http://www.bat.com/group/sites/UK 8GLKJF.nsf/vwPagesWebLive/3FF4B58C81321BC8C12578880056EF37/\$FILE/14_ Mark\%20Cobben\%20-\%20Capsule\%20Rollout.pdf?openelement (accessed 2 May 2013).

11 Canadian Intellectual Property Office. http://www.ic.gc.ca/app/opic-cipo/trdmrks/srch/ vwTrdmrk.do?lang=eng\&status=\&fileNumber $=1534247$ \&extension $=0$ \&starting DocumentIndexOnPage $=1$ (accessed 4 May 2013).

12 Communispace. RJ Reynolds. Burning Thoughts Pulse Reports Weeks 3 and 4. 2006. Bates No: 541156202-6224. http://legacy.library.ucsf.edu/tid/uwc87h00/ (accessed 15 Mar 2012).

13 Poezl M in Mohan AM. Kent Cigarette Multipack Carton Lights Up with Integrated Electronics. Packaging Digest 2007 Jan. http://www.packagingdigest.com/article/ 341456-Kent_cigarette_multipacks_carton_lights_up_with_integrated_electronics. php (accessed 2 May 2013).

14 Campbell SW, Park YJ. Social implications of mobile telephony: the rise of personal communication society. Sociol Compass 2008;2:371-87.

15 Skog B. Mobiles and the Norwegian teen: identity, gender, and class. In: Ketz JE, Aakhus MA, eds. Perpetual contact: mobile communication, private talk, public performance. Cambridge, UK: Cambridge University Press, 2002:255-73.

16 Castells M. Mobile Communication and society: a global perspective. Cambridge, MA: MIT Press, 2007.

17 Ling R, Yttri B. Control, emancipation and status: the mobile telephone in the teen's parental and peer group control relationships. In: Kraut R, Brynim M, Kiesler $S$, eds. Computers, phones, and the internet: domesticating information technology. Oxford, UK: Oxford University Press, 2006:219-34. 